13,11

\title{
Структурные фазовые превращения при твердофазной реакции в тонких двухслойных пленках $\mathrm{Al} / \mathrm{Pt}$
}

\author{
(C) P.P. Алтунин ${ }^{1}$, E.T. Моисеенко ${ }^{1}$, С.М. Жарков ${ }^{2,1}$ \\ ${ }^{1}$ Сибирский фредеральный университет, \\ Красноярск, Россия \\ ${ }^{2}$ Институт ффизики им. Л.В. Киренского ФИЦ КНЦ СО РАН, \\ Красноярск, Россия \\ E-mail: raltunin@gmail.com
}

(Поступила в Редакцию 20 декабря 2017 г.)

\begin{abstract}
Методом in situ дифракции электронов исследована последовательность фаз, формирующихся в процессе твердофазной реакции в тонких двухслойных пленках Al/Pt. Показано, что первой в процессе твердофазной реакции, инициированной термическим нагревом, формируется аморфная фаза $\mathrm{PtAl}_{2}$. В ходе дальнейшего нагрева последовательно формируются кристаллические фазы: $\mathrm{PtAl}_{2}, \mathrm{Pt}_{2} \mathrm{Al}_{3}, \mathrm{PtAl}_{2} \mathrm{Pt}_{3} \mathrm{Al}$, что качественно согласуется с моделью эффективной теплоты формирования. Проведен количественный анализ содержания фаз, формирующихся в процессе реакции, исследованы структурные фазовые превращения.
\end{abstract}

Работа выполнена при финансовой поддержке Российского фонда фундаментальных исследований (грант № 16-33-00475 мол_а).

DOI: $10.21883 /$ FTT.2018.07.46130.352

\section{1. Введение}

Соединения с алюминием широко используются в микроэлектронной промышленности в качестве электроконтактов, металлизирующих слоев, диффузионных барьеров, а также применяются для повышения устойчивости систем к электромиграции [1-3]. Интерметаллические соединения $\mathrm{Al}-\mathrm{Pt}$ применяются в микроэлектронных устройствах [4,5], обладают эффектом памяти формы [6], могут использоваться в качестве огнеупорных сплавов $[7,8]$ и в конструкциях солнечных элементов [9].

Надежность микроэлектронных устройств определяется стабильностью физико-химических свойств тонкопленочных систем, входящих в состав электронных компонентов. В связи с этим актуально исследование процессов твердофазных реакций, протекающих на границе раздела нанослоев различного состава. В результате твердофазной реакции образуются новые соединения с физико-химическими свойствами, отличными от свойств исходной тонкопленочной системы. Например, нагрев двухслойной тонкопленочной системы $\mathrm{Al} / \mathrm{Pt}$, используемой в устройствах сегнетоэлектрической оперативной памяти (FeRAM) [10,11], до 200-300 ${ }^{\circ} \mathrm{C}$ приводит к выходу из строя этих устройств в результате образования на границе раздела между слоями алюминия и платины интерметаллических соединений.

Необходимо отметить, что экспериментально наблюдаемая фазовая последовательность при твердофазной реакции в тонких пленках $\mathrm{Al} / \mathrm{Pt}$ не поддается описанию ни одной из современных теоретических моделей. Теоретические расчеты, проведенные в рамках моделей эффективной теплоты формирования (Effective Heat of
Formation, EHF) [12] и Walser-Bene [13], показывают, что первой в процессе твердофазной реакции должна формироваться фаза $\mathrm{Pt}_{5} \mathrm{Al}_{21}$. Однако, в экспериментальных работах $[14,15]$ первой наблюдали формирование аморфной фазы $\mathrm{PtAl}_{2}$, а в [16-19] - кристаллической фазы $\mathrm{Pt}_{2} \mathrm{Al}_{3}$. Анализ литературных данных показал, что большинство исследований твердофазных реакций в пленках $\mathrm{Al} / \mathrm{Pt}$ сосредоточено на начальном этапе. Существует совсем немного работ, например $[18,20]$, посвященных исследованию полной фазовой последовательности. Возможно, это связано с тем, что при твердофазных реакциях в системе $\mathrm{Al}-\mathrm{Pt}$ формируется большое количество интерметаллических соединений, идентифицировать которые достаточно сложно [18]. Стоит отметить, что большинство исследований процессов твердофазных реакций в тонкопленочных системах $\mathrm{Al} / \mathrm{Pt}$ проведено после длительного термического отжига при фиксированной температуре. В этом случае исследование фазового состава проводится только на определенных этапах эксперимента, что не позволяет определить точную последовательность фаз, формирующихся в процессе твердофазной реакции. Представляет интерес и тот факт, что в тонких пленках толщиной $<100 \mathrm{~nm}$, в отличие от пленок толщиной $\gg 100 \mathrm{~nm}$, формируются не все фазы, присутствующие на равновесной фазовой диаграмме [12].

Целью настоящей работы является установление последовательности образования фаз, формирующихся в процессе твердофазной реакции в тонких двухслойных пленках $\mathrm{Al} / \mathrm{Pt}$. Исследование проведено методом in situ дифракции электронов, что позволило изучить изменение фазового состава непосредственно в процессе твердофазной реакции. 


\section{2. Методы получения и исследования образцов}

Тонкие двухслойные пленки $\mathrm{Al} / \mathrm{Pt}$, исследованные в настоящей работе, получены методом электроннолучевого испарения на высоковакуумной установке MED-020 (Bal-Tec). Напыление производилось в вакууме при остаточном давлении $5 \cdot 10^{-5} \mathrm{~Pa}$. Контроль толщины пленок осуществляли при помощи кварцевого резонатора QSG-100, который позволяет контролировать интегральную толщину пленок с точностью до $0.01 \mathrm{~nm}$. Толщины индивидуальных слоев алюминия и платины подбирали таким образом, чтобы получить атомное соотношение $\mathrm{Al}: \mathrm{Pt} \approx 1: 1$. В качестве подложки использовали свежесколотый монокристалл $\mathrm{NaCl}$, а также покровное стекло. Для напыления использовали материалы ADVENT [21] высокой степени чистоты: Pt (99.99\%); Al (99.999\%). Для проведения электронномикроскопических исследований, пленки, напыленные на $\mathrm{NaCl}$, отделяли от подложки в дистиллированной воде и высаживали на поддерживающие электронно-микроскопические сеточки, изготовленные из молибдена.

Микроструктура и элементный состав тонких пленок исследованы с помощью просвечивающего электронного микроскопа JEOL JEM-2100 (при ускоряющем напряжении $200 \mathrm{kV}$ ), оборудованного энергодисперсионным спектрометром Oxford Inca x-sight. Фазовый состав исследованных образцов определяли на основе анализа картин дифракции электронов, полученных методом микродифракции от областей диаметром $\approx 0.1-1.0 \mu \mathrm{m}$. Нагрев осуществляли непосредственно в колонне просвечивающего электронного микроскопа JEM-2100 (базовый вакуум $\left.1 \cdot 10^{-6} \mathrm{~Pa}\right)$, используя специальный держатель образцов (Gatan Model 652 Double Tilt Heating Holder), предназначенный для контролируемого нагрева образцов от комнатной температуры до $+1000^{\circ} \mathrm{C}$. Этот метод был успешно использован для исследования процессов твердофазных реакций в тонкопленочных системах $\mathrm{Fe} / \mathrm{Pd}[22,23], \mathrm{Fe} / \mathrm{Si}$ [24].

Экспериментально полученные картины дифракции электронов проанализированы с использованием программного комплекса Process Diffraction [25] с целью установления количественного содержания фаз, формирующихся в процессе твердофазной реакции. Как показано в работе [25], относительная погрешность определения содержания отдельной фазы при помощи данного программного комплекса составляет $\pm 10 \%$. Абсолютная интенсивность дифракционных рефлексов рассчитана теоретически при помощи программного пакета Endeavour [26].

\section{3. Экспериментальные результаты}

Получена серия тонких двухслойных пленок $\mathrm{Al} / \mathrm{Pt}$ с суммарной толщиной до $50 \mathrm{~nm}$. Электронно-микроскопические исследования пленок $\mathrm{Al} / \mathrm{Pt}$ в исходном

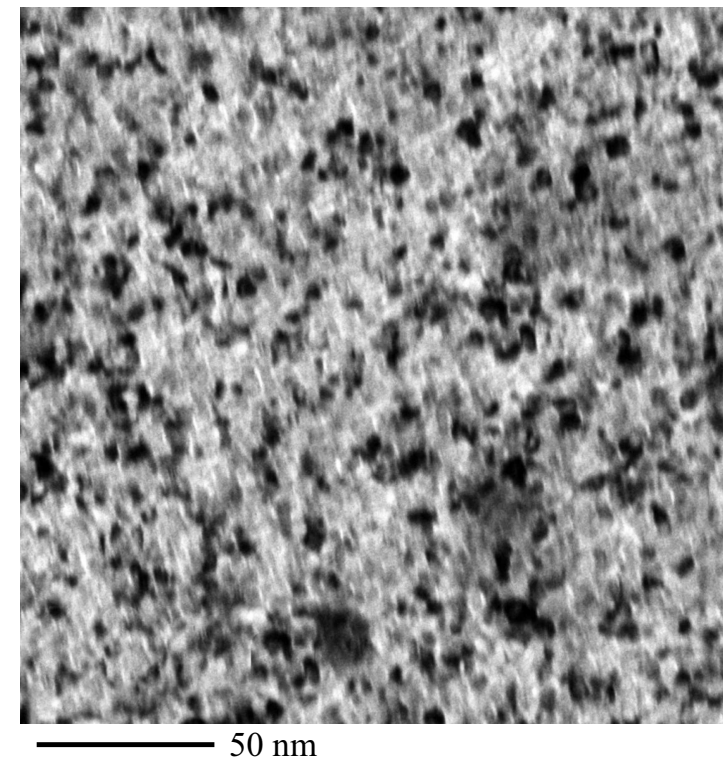

$a$

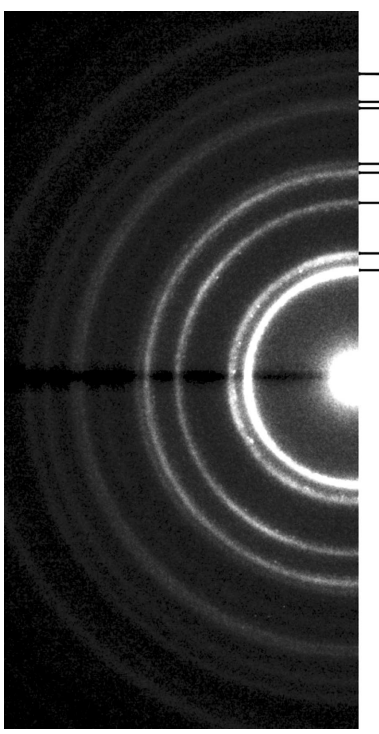

$0.80 \AA$ (422) $\mathrm{Pt}$ $\frac{0.83 \AA(422) \mathrm{Al}}{0.87 \AA(420) \mathrm{Pt}}$ $0.91 \AA(420) \mathrm{Al}$ $0.93 \AA$ (331) Al $1.13 \AA$ (222) $\mathrm{Pt}$ $1.17 \AA(222) \mathrm{Al}$ $1.18 \AA$ (311) $\mathrm{Pt}$ $1.22 \AA(311) \mathrm{Al}$ $1.38 \AA(220) \mathrm{Pt}$ $1.43 \AA(220) \mathrm{Al}$ $1.96 \AA(200) \mathrm{Pt}$ $2.02 \AA(200) \mathrm{Al}$ $2.26 \AA$ (111) Pt $2.34 \AA(111) \mathrm{Al}$

Рис. 1. Электронно-микроскопическое изображение $(a)$ и картина дифракции электронов $(b)$, полученные от пленки $\mathrm{Al} / \mathrm{Pt}$ в исходном состоянии.

состоянии показали, что размер кристаллитов платины составлял 4-6 nm, размер кристаллитов алюминия 5-20 nm (рис. 1,a). Картина дифракции электронов (рис. $1, b)$, полученная от пленки в исходном состоянии, содержит дифракционные рефлексы, принадлежащие гранецентрированным кубическим (ГЦК) фазам: $\mathrm{Al}$ (пространственная группа $F m \overline{3} m$, параметр решетки $a=4.05 \AA)$ и $\mathrm{Pt}$ (пространственная группа $F m \overline{3} m$, параметр решетки $a=3.91 \AA)$.

С целью получения информации о процессах фазообразования при твердофазной реакции проведена серия нагревов пленок $\mathrm{Al} / \mathrm{Pt}$ от комнатной температуры до $500^{\circ} \mathrm{C}$ со скоростью $10^{\circ} \mathrm{C} / \mathrm{min}$. Одновременно с нагревом образца производили регистрацию картин дифрак- 
Структурные фазовые превращения при твердофазной реакции в тонких двухслойных пленках $\mathrm{Al} / \mathrm{Pt}$

\begin{tabular}{|c|c|c|c|c|c|c|c|c|c|}
\hline \multirow{2}{*}{ Фаза } & \multicolumn{9}{|c|}{ Температура, ${ }^{\circ} \mathrm{C}$} \\
\hline & $25-269$ & $270-287$ & $288-300$ & $301-349$ & $350-389$ & $390-429$ & $430-459$ & $460-497$ & $498-500$ \\
\hline $\begin{array}{c}\mathrm{Al} \\
\mathrm{Pt} \\
\mathrm{PtAl}_{2} \text { (аморфная) } \\
\mathrm{PtAl}_{2} \\
\mathrm{Pt}_{2} \mathrm{Al}_{3} \\
\mathrm{PtAl} \\
\mathrm{Pt}_{5} \mathrm{Al}_{3} \\
\mathrm{Pt}_{2} \mathrm{Al} \\
\mathrm{Pt}_{3} \mathrm{Al}\end{array}$ & $\begin{array}{l}+ \\
+\end{array}$ & $\begin{array}{l}+ \\
+ \\
+\end{array}$ & $\begin{array}{l}+ \\
+ \\
+ \\
\mathrm{s} \\
+\end{array}$ & $\begin{array}{l}+ \\
\text { s } \\
+\end{array}$ & $\begin{array}{l}+ \\
\mathbf{s} \\
+ \\
+\end{array}$ & $\begin{array}{l}+ \\
\text { s } \\
+ \\
+ \\
? \\
? \\
\text { s }\end{array}$ & $\begin{array}{c}\mathbf{s} \\
+ \\
+ \\
+ \\
+\end{array}$ & $\begin{array}{l}+ \\
+ \\
+\end{array}$ & $\begin{array}{l}\mathrm{s} \\
+ \\
\mathrm{s}\end{array}$ \\
\hline
\end{tabular}

Примечание. Символ „s“ означает, что фаза присутствует в пленке лишь в небольшом количестве (< 10 wt.\%). Символ „?“ означает, что присутствие фазы не исключено.

ции электронов со скоростью четыре кадра в минуту, таким образом, один кадр соответствовал изменению температуры образца на $2.5^{\circ} \mathrm{C}$. Анализ картин дифракции электронов позволил изучить изменение фазового состава пленок. В таблице представлена информация о фазах, формирующихся в пленке в процессе твердофазной реакции.

Начало твердофазной реакции между нанослоями алюминия и платины регистрировали при температуре $\approx 270^{\circ} \mathrm{C}$, что сопровождалось появлением диффузных гало слабой интенсивности на картинах дифракции электронов. Наблюдаемые гало соответствуют межплоскостным расстояниям $\approx 3.4 \AA$, $\approx 2.9 \AA$ и $\approx 2.1 \AA$, которые могут быть приписаны дифракционным рефлексам $d(111)=3.41 \AA, d(200)=2.95 \AA$ и $d(220)=2.09 \AA$ фазы $\mathrm{PtAl}_{2}$ (пространственная группа $F m \overline{3} m$, параметр решетки $a=5.91 \AA$ ). Это согласуется с результатами работ $[14,15]$, в которых показано, что твердофазная реакция в пленках $\mathrm{Al} / \mathrm{Pt}$ начинается с образования аморфной фазы, элементный состав которой близок к $\mathrm{PtAl}_{2}$.

При температуре $288^{\circ} \mathrm{C}$ на картине дифракции электронов наблюдали появление дифракционных рефлексов слабой интенсивности, соответствующих кристаллической фазе $\mathrm{PtAl}_{2}: d(111)=3.41 \AA, d(220)=2.09 \AA \quad$ и $d(311)=1.78 \AA$, это свидетельствует о начале перехода данной фазы из аморфного в кристаллическое состояние. При $T=291^{\circ} \mathrm{C}$ отмечали появление дифракционных рефлексов фазы $\mathrm{Pt}_{2} \mathrm{Al}_{3}$ (пространственная группа $P \overline{3} m 1$; параметры решетки: $a=4.21 \AA, c=5.17 \AA$ ): $d(001)=5.17 \AA, \quad d(101)=2.98 \AA \quad$ и $\quad d(012)=2.11 \AA$. При температуре $350^{\circ} \mathrm{C}$ наблюдали появление рефлексов фазы PtAl (пространственная группа $P m \overline{3} m$, параметр решетки $a=3.04 \AA$ ), а при $390^{\circ} \mathrm{C}$ рефлексов фазы $\mathrm{Pt}_{3} \mathrm{Al}$ (пространственная группа $P m \overline{3} m, a=3.87 \AA$ ).

Электронно-микроскопические исследования тонких пленок $\mathrm{Al} / \mathrm{Pt}$ после нагрева до $500^{\circ} \mathrm{C}$ показали, что пленки состоят из кристаллитов со средним размером $\approx 15-25 \mathrm{~nm}$ (рис. 2,a). Картина дифракции электронов (рис. $2, b$ ), полученная после нагрева пленки до $500^{\circ} \mathrm{C}$,

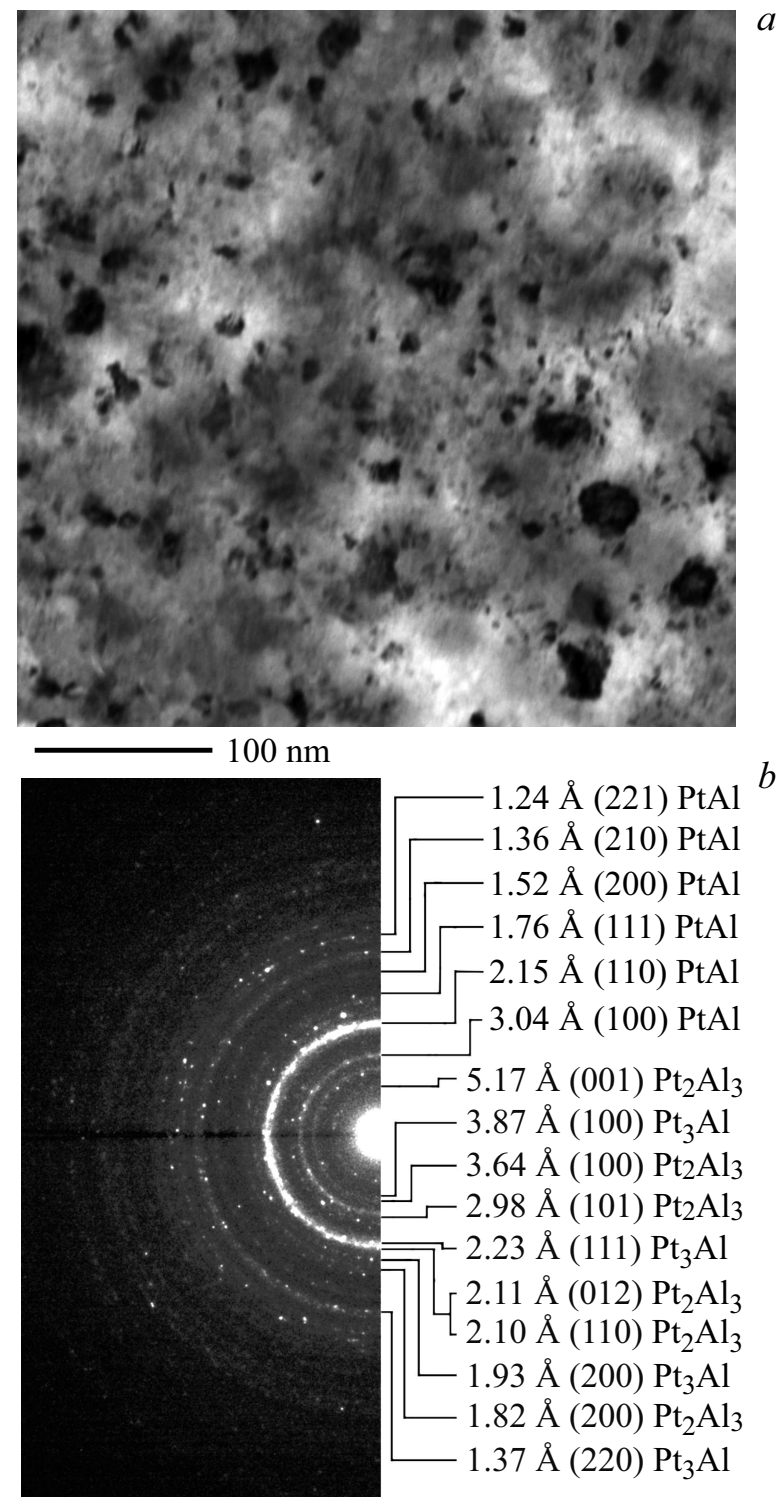

Рис. 2. Электронно-микроскопическое изображение $(a)$ и картина дифракции электронов $(b)$, полученные от пленки $\mathrm{Al} / \mathrm{Pt}$ после нагрева до $500^{\circ} \mathrm{C}$. 


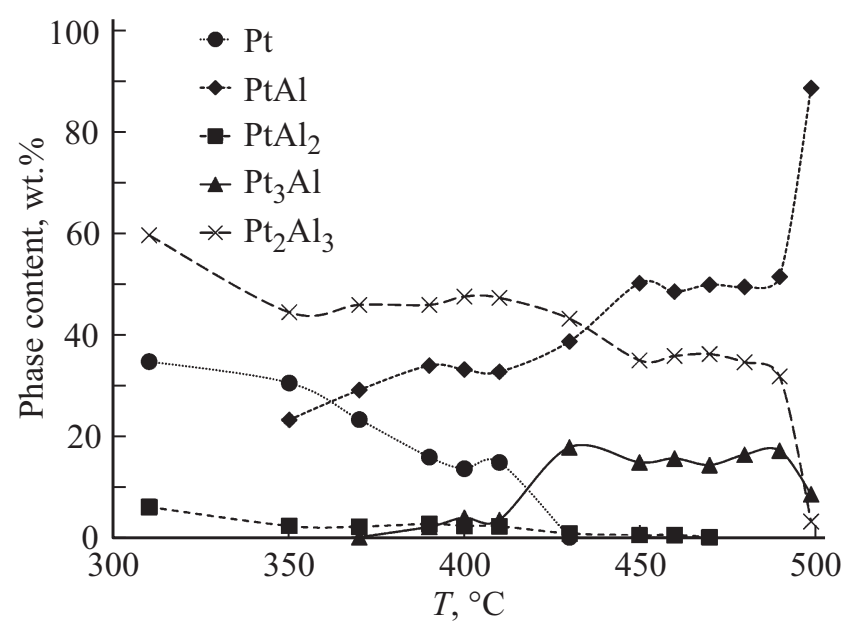

Рис. 3. Изменение фазового состава при твердофазной реакции в пленках $\mathrm{Al} / \mathrm{Pt}(\mathrm{wt} . \%)$.

содержит дифракционные рефлексы фаз: $\mathrm{PtAl}, \mathrm{Pt}_{2} \mathrm{Al}_{3}$, $\mathrm{Pt}_{3} \mathrm{Al}$. При этом суммарное содержание фаз $\mathrm{Pt}_{2} \mathrm{Al}_{3}$ и $\mathrm{Pt}_{3} \mathrm{Al}$ составляет менее $10 \mathrm{wt} . \%$.

С целью исследования структурно-фазовых превращений проведен количественный анализ содержания фаз, формирующихся в процессе твердофазной реакции. Необходимо отметить, что количественная оценка содержания фазы ГЦК алюминия на основании анализа интенсивности дифракционных рефлексов на картинах дифракции электронов затруднена из-за того, что параметры кристаллических решеток ГЦК алюминия и платины отличаются всего на $3.5 \%$, поэтому соответствующие им дифракционные рефлексы расположены достаточно близко друг к другу. При этом абсолютная интенсивность дифракционных рефлексов ГЦК алюминия почти на порядок меньше интенсивности аналогичных рефлексов платины (для $\mathrm{Al} I_{a b s}(111)=509$, для Pt $\left.I_{a b s}(111)=4856\right)$. Вследствие приведенных выше причин становится невозможной количественная оценка содержания фазы ГЦК алюминия в присутствии ГЦК платины. Поэтому, до тех пор пока в образце присутствует фаза ГЦК алюминия $\left(\approx 300^{\circ} \mathrm{C}\right)$, невозможно проведение количественного анализа содержания формирующихся фаз.

Количественный анализ содержания фаз, формирующихся в процессе твердофазной реакции, проведен в температурном диапазоне от 310 до $500^{\circ} \mathrm{C}$. На рис. 3 представлено изменение фазового состава в процессе твердофазной реакции в пленках $\mathrm{Al} / \mathrm{Pt}$, содержание индивидуальных фаз приведено в весовых процентах. Необходимо отметить, что количественный анализ становится возможным только после того, как дифракционные рефлексы формирующихся фаз достигнут достаточной интенсивности. В случае фазы PtAl абсолютная интенсивность дифракционного рефлекса, обладающего максимальной интенсивностью, $I_{a b s}(110)=709$, что значительно меньше абсолютной интенсивности рефлек- сов: $\mathrm{Pt}-I_{a b s}(111)=4856, \mathrm{PtAl}_{2}-I_{a b s}(220)=16148$, $\mathrm{Pt}_{2} \mathrm{Al}_{3}-I_{a b s}(110)=1682$, также обладающих максимальной интенсивностью для данных фаз. При этом дифракционные рефлексы фаз $\mathrm{PtAl}$, ГЦК платины, $\mathrm{Pt}_{2} \mathrm{Al}_{3}$ и $\mathrm{PtAl}_{2}$, обладающие максимальной интенсивностью, расположены на картине дифракции электронов достаточно близко друг к другу. Поэтому не удается определить точную температуру начала формирования фазы PtAl, a анализ содержания данной фазы становится возможным только при достижении температуры $350^{\circ} \mathrm{C}$ (см. рис. 3), когда содержание фазы PtAl составляет $\approx 20$ wt.\%.

\section{4. Обсуждение}

На основании анализа полученных экспериментальных результатов установлено, что в процессе твердофазной реакции в тонких двухслойных пленках $\mathrm{Al} / \mathrm{Pt}$ интерметаллические соединения формируются в следующей последовательности (см. таблицу):

$$
\begin{aligned}
\mathrm{Pt}+\mathrm{Al} & \Rightarrow \mathrm{PtAl}_{2} \text { (аморф.) } \Rightarrow \mathrm{PtAl}_{2} \text { (кристалл.) } \\
& \Rightarrow \mathrm{Pt}_{2} \mathrm{Al}_{3} \Rightarrow \mathrm{PtAl} \Rightarrow \mathrm{Pt}_{3} \mathrm{Al}
\end{aligned}
$$

Показано, что в тонких двухслойных пленках $\mathrm{Al} / \mathrm{Pt}$ в процессе нагрева при достижении температуры $\approx 270^{\circ} \mathrm{C}$ начинается формирование аморфной фазы $\mathrm{PtAl}_{2}$. В экспериментальных работах $[14,15]$ в процессе твердофазной реакции первой формируется аморфная фаза $\mathrm{PtAl}_{2}$ при нагреве до температуры $200^{\circ} \mathrm{C}$ [15] и $300^{\circ} \mathrm{C}$ [14], в работах [16-19] первой формируется кристаллическая фаза $\mathrm{Pt}_{2} \mathrm{Al}_{3}$ после отжигов при температуре $200-300^{\circ} \mathrm{C}$. Однако, как было показано ранее, формирование фазы $\mathrm{PtAl}_{2}$ в качестве первой фазы не согласуется с теоретическими расчетами моделей EHF [12] и Walser-Bene [13], которые предсказывают, что в процессе твердофазной реакции на границе раздела $\mathrm{Al} / \mathrm{Pt}$ первой должна формироваться фаза $\mathrm{Pt}_{5} \mathrm{Al}_{21}$. Необходимо отметить, что модель EHF [12], в отличие от модели Walser-Bene [13], учитывает кинетические (эффективная концентрация) и термодинамические (теплота формирования) параметры, что позволяет ей предсказывать не только первую фазу, но и полную фазовую последовательность. Последовательность формирования фаз в процессе твердофазной реакции, согласно модели EHF, выглядит следующим образом (в скобках приведены значения эффективной теплоты формирования для данной фазы) [12]

$$
\begin{aligned}
\mathrm{Pt}_{5} \mathrm{Al}_{21} & (-5.94 \mathrm{~kJ} / \mathrm{mol}) \Rightarrow \mathrm{Pt}_{8} \mathrm{Al}_{21}(-5.14 \mathrm{~kJ} / \mathrm{mol}) \\
& \Rightarrow \mathrm{PtAl}_{2}(-5.05 \mathrm{~kJ} / \mathrm{mol}) \Rightarrow \mathrm{Pt}_{2} \mathrm{Al}_{3}(-4.75 \mathrm{~kJ} / \mathrm{mol}) \\
& \Rightarrow \operatorname{PtAl}(-4.00 \mathrm{~kJ} / \mathrm{mol}) \Rightarrow \mathrm{Pt}_{5} \mathrm{Al}_{3}(-2.82 \mathrm{~kJ} / \mathrm{mol}) \\
& \Rightarrow \mathrm{Pt}_{2} \mathrm{Al}(-2.64 \mathrm{~kJ} / \mathrm{mol}) \Rightarrow \mathrm{Pt}_{3} \mathrm{Al}(-1.87 \mathrm{~kJ} / \mathrm{mol}) .
\end{aligned}
$$

Фазы с наименьшей эффективной теплотой формирования должны формироваться раньше остальных. 
Фазы $\mathrm{Pt}_{5} \mathrm{Al}_{21}$ и $\mathrm{Pt}_{8} \mathrm{Al}_{21}$ имеют наименьшие значения эффективной теплоты формирования, однако, как показано в работе [12], из-за существования нуклеационного барьера формирование данных фаз в тонких пленках может быть затруднено. Возможно, поэтому в настоящей работе первой наблюдается образование фазы $\mathrm{PtAl}_{2}$, формирующейся в аморфном состоянии. В ходе дальнейшего нагрева практически одновременно формируются кристаллические фазы $\mathrm{PtAl}_{2}$ и $\mathrm{Pt}_{2} \mathrm{Al}_{3}$, что объясняется небольшой разницей $(\approx 6 \%)$ значений эффективной теплоты формирования данных фаз (соответственно -5.05 и $-4.75 \mathrm{~kJ} / \mathrm{mol})$. Подобное явление наблюдали ранее при твердофазной реакции в тонких пленках $\mathrm{Al} / \mathrm{Au}$ [27]: значительный рост интерметаллических соединений $\mathrm{Al}_{2} \mathrm{Au}_{5}$ и $\mathrm{AlAu}_{2}$ начинался практически одновременно, что также связано с минимальной разницей значений эффективной теплоты формирования (соответственно -20.0 и $-19.8 \mathrm{~kJ} / \mathrm{mol}$ ). Последовательное формирование фаз $\mathrm{Pt}_{2} \mathrm{Al}_{3} \Rightarrow \mathrm{PtAl} \Rightarrow \mathrm{Pt}_{3} \mathrm{Al}$, наблюдаемое в настоящей работе в процессе твердофазной реакции, соответствует фазовой последовательности, полученной в работе [18], и объясняется увеличением эффективной теплоты формирования фаз $\mathrm{Pt}_{2} \mathrm{Al}_{3}(-4.75 \mathrm{~kJ} / \mathrm{mol}) \Rightarrow \mathrm{PtAl}(-4.00 \mathrm{~kJ} / \mathrm{mol}) \Rightarrow$ $\Rightarrow \mathrm{Pt}_{3} \mathrm{Al}(1.87 \mathrm{~kJ} / \mathrm{mol})$.

Количественный анализ содержания фаз в процессе твердофазной реакции показал, что в температурном диапазоне $310-410^{\circ} \mathrm{C}$ происходит уменьшение содержания фаз ГЦК платины, $\mathrm{Pt}_{2} \mathrm{Al}_{3}$ и $\mathrm{PtAl}_{2}$ (см. рис. 3). Также на этом этапе происходит образование фазы $\mathrm{PtAl}$, однако из-за слабых абсолютных интенсивностей дифракционных рефлексов данной фазы ее однозначная идентификация становится возможной только при достижении температуры $350^{\circ} \mathrm{C}$. Увеличение содержания фазы PtAl в температурном диапазоне $310-410^{\circ} \mathrm{C}$ происходит за счет снижения содержания фаз $\mathrm{Pt}_{2} \mathrm{Al}_{3}, \mathrm{PtAl}_{2}$ и ГЦК платины. В ходе дальнейшего нагрева увеличение содержания фазы PtAl происходит преимущественно за счет уменьшения содержания фазы $\mathrm{Pt}_{2} \mathrm{Al}_{3}$ в температурном диапазоне $410-500^{\circ} \mathrm{C}$ и фазы $\mathrm{Pt}_{3} \mathrm{Al}$ в температурном диапазоне $490-500^{\circ} \mathrm{C}$. Дальнейший отжиг при температуре $500^{\circ} \mathrm{C}$ в течение $30 \mathrm{~min}$ привел лишь к незначительному увеличению содержания фазы PtAl.

Таким образом, в температурном диапазоне 350-500 ${ }^{\circ} \mathrm{C}$ происходит структурное фазовое превращение $\mathrm{Pt}_{2} \mathrm{Al}_{3} \Rightarrow \mathrm{PtAl}$, а в температурном диапазоне $490-500^{\circ} \mathrm{C}-\mathrm{Pt}_{3} \mathrm{Al}+\mathrm{Pt}_{2} \mathrm{Al}_{3} \Rightarrow \mathrm{PtAl}$. Количественный анализ содержания фаз (рис. 3) показал, что в температурном диапазоне $410-430^{\circ} \mathrm{C}$ увеличение содержания фазы $\mathrm{Pt}_{3} \mathrm{Al}$ происходит за счет структурного фазового превращения $\mathrm{Pt}+\mathrm{PtAl} \Rightarrow \mathrm{Pt}_{3} \mathrm{Al}$, одновременно происходит структурное фазовое превращение $\mathrm{Pt}_{2} \mathrm{Al}_{3} \Rightarrow \mathrm{PtAl}$, обеспечивая увеличение содержания фазы PtAl.

Стоит отметить, что в настоящей работе в процессе твердофазной реакции не обнаружено формирование следующих интерметаллических соединений: $\mathrm{Pt}_{5} \mathrm{Al}_{21}$, $\mathrm{Pt}_{8} \mathrm{Al}_{21}, \mathrm{Pt}_{5} \mathrm{Al}_{3}$ и $\mathrm{Pt}_{2} \mathrm{Al}$. Отсутствие фаз $\mathrm{Pt}_{5} \mathrm{Al}_{21}$ и $\mathrm{Pt}_{8} \mathrm{Al}_{21}$ можно объяснить с точки зрения существования нуклеационных барьеров [12]. Что касается фаз $\mathrm{Pt}_{5} \mathrm{Al}_{3}$ и $\mathrm{Pt}_{2} \mathrm{Al}$, то, согласно модели ЕНF, они должны формироваться раньше, чем $\mathrm{Pt}_{3} \mathrm{Al}$, однако основные дифракционные рефлексы всех трех фаз совпадают. Различить их можно только в том случае, когда они присутствуют в достаточном количестве и на картине дифракции электронов наблюдается полный набор рефлексов. В температурном диапазоне от $390^{\circ} \mathrm{C}$ до $429^{\circ} \mathrm{C}$ наблюдаются дифракционные рефлексы слабой интенсивности, которые могут соответствовать как одной из фаз $\mathrm{Pt}_{3} \mathrm{Al}, \mathrm{Pt}_{5} \mathrm{Al}_{3}, \mathrm{Pt}_{2} \mathrm{Al}$, так и их смеси. И только при достижении $430^{\circ} \mathrm{C}$ можно однозначно утверждать, что в пленке присутствует фаза $\mathrm{Pt}_{3} \mathrm{Al}$ с содержанием $\approx 18 \mathrm{wt} . \%$.

\section{5. Заключение}

Исследованы структурные фазовые превращения и установлена последовательность формирования фаз в процессе твердофазной реакции в тонких двухслойных пленках Al/Pt (суммарная толщина до $50 \mathrm{~nm}$, атомное соотношение $\mathrm{Al}: \mathrm{Pt} \approx 1: 1)$. Исследование проведено методом in situ дифракции электронов непосредственно в процессе твердофазной реакции, инициированной термическим нагревом в колонне просвечивающего электронного микроскопа. Показано, что при температуре $\approx 270^{\circ} \mathrm{C}$ в результате реакции между слоями алюминия и платины первой формируется аморфная фаза $\mathrm{PtAl}_{2}$. В ходе дальнейшего нагрева последовательно формируются кристаллические фазы $\mathrm{PtAl}_{2}, \mathrm{Pt}_{2} \mathrm{Al}_{3}, \mathrm{PtAl}, \mathrm{Pt}_{3} \mathrm{Al}$, что качественно согласуется с моделью эффективной теплоты формирования. Проведен количественный анализ содержания фаз, формирующихся в процессе твердофазной реакции. Показано, что в температурном диапазоне $310-410^{\circ} \mathrm{C}$ происходит образование фазы PtAl за счет снижения содержания фаз ГЦК платины, $\mathrm{Pt}_{2} \mathrm{Al}_{3}$ и $\mathrm{PtAl}_{2}$. В температурном диапазоне $410-430^{\circ} \mathrm{C}$ за счет структурного фазового превращения $\mathrm{Pt}+\mathrm{PtAl} \Rightarrow \mathrm{Pt}_{3} \mathrm{Al}$ происходит увеличение содержания фазы $\mathrm{Pt}_{3} \mathrm{Al}$, одновременно происходит структурное фазовое превращение $\mathrm{Pt}_{2} \mathrm{Al}_{3} \Rightarrow \mathrm{PtAl}$, обеспечивая увеличение содержания фазы PtAl. В ходе дальнейшего нагрева увеличение содержания фазы PtAl (до $\approx 90 \mathrm{wt} . \%$ ) происходит за счет уменьшения содержания фаз $\mathrm{Pt}_{2} \mathrm{Al}_{3}$ и $\mathrm{Pt}_{3} \mathrm{Al}$.

\section{Список литературы}

[1] E.G. Colgan. Mater. Sci. Rep. 5, 1 (1990).

[2] The Chemistry of Metal CVD / Eds T.T. Kodas, M.J. Hampden-Smith. John Wiley\&Sons (2008). 562 p.

[3] А.С. Рогачев. Успехи химии 77, 22 (2008).

[4] D.P. Adams. Thin Solid Films 576, 98 (2015).

[5] B.K. Crone, I.H. Campbell, P.S. Davids, D.L. Smith, C.J. Neef, J.P. Ferraris. J. Appl. Phys. 86, 5767 (1999).

[6] T. Biggs, M.B. Cortie, M.J. Witcomb, L.A. Cornish. Platin. Met. Rev. 47, 142 (2003). 
[7] R. Volk1, Y. Yamabe-Mitarai, C. Huang, H. Harada. Met. Mater. Trans. A 36, 2881 (2005).

[8] W.S. Walston. Proc. X Int. Symp. Superalloys-2004 / Ed. K.A. Green, T.M. Pollock, H. Harada, T.E. Howson, R.C. Reed, J.J. Schirra, S. Walston, 579 (2004).

[9] Y. Noh, O. Song. Korean J. Met. Mater. 52, 61 (2014).

[10] K.W. Cho, T.W. Hong, S.Y. Kweon, S.K. Choi. Korean J. Mater. Res. 14, 688 (2004).

[11] Y.S. Hwang, J.W. Lee, S.Y. Lee, B.J. Koo, D.J. Jung, Y.S. Chun, M.H. Lee, D.W. Shin, S.H. Shin, S.E. Lee, B.H. Kim, N.S. Kang, K.N. Kim. Jpn. J. Appl. Phys. 37, 1332 (1998).

[12] R. Pretorius, T.K. Marais, C.C. Theron. Mater. Sci. Rep. 10, 1 (1993).

[13] R.W. Bene. Appl. Phys. Lett. 41, 529 (1982).

[14] P. Gas, C. Bergman, G. Clugnet, P. Barna, A. Kovacs, J. Labar. Defect Diffus. Forum 194-199, 807 (2001).

[15] J.L. Labar, A. Kovacs, P.B. Barna. J. Appl. Phys. 90, 6545 (2001).

[16] X.A. Zhao, E. Ma, H.Y. Yang, M.A. Nicolet. Thin Solid Films 153, 379 (1987).

[17] E. Ma, M.A. Nicolet. Phys. Status Solidi A 110, 509 (1988).

[18] E.G. Colgan. J. Appl. Phys. 62, 1224 (1987).

[19] M. Nastasi, L.S. Hung, J.W. Mayer. Appl. Phys. Lett. 43, 831 (1983).

[20] S.P. Murarka, I.A. Blech, H.J. Levinstein. J. Appl. Phys. 47, 5175 (1976).

[21] ADVENT Research Materials Ltd, Oxford, U.K., www.advent-rm.com.

[22] С.М. Жарков, Е.Т. Моисеенко, Р.Р. Алтунин, Н.С. Николаева, В.С. Жигалов, В.Г. Мягков. Письма в ЖЭТФ 99, 472 (2014).

[23] Е.Т. Моисеенко, Р.Р. Алтунин, С.М. Жарков. ФТТ 59, 1208 (2017).

[24] S.M. Zharkov, R.R. Altunin, E.T. Moiseenko, G.M. Zeer, S.N. Varnakov, S.G. Ovchinnikov. Solid State Phenom. 215, 144 (2014).

[25] J.L. Labar. Microsc. Microanal. 15, 20 (2009).

[26] H. Putz, J.C. Schön, M. Jansen. J. Appl. Crystallogr. 32, 864 (1999).

[27] G. Majni, C. Nobili, G. Ottaviani, M. Costato. J. Appl. Phys. 52, 4047 (1981).

Редактор Е.Ю. Флегонтова 